\title{
Researches on the Variations of Oceanographic Conditions in the Region of the Ocean Weather Station "Extra" in the North Pacific Ocean (I)
}

_ "Normal" Values and Annual Variations of Oceanographic Elements -

by

M. Koizumi .

Meteorological Research Institute.

(Received August 22, 1955)

\begin{abstract}
Oceanographic data of the Ocean Weather Stations "Extra" $\left(39^{\circ}\right.$ $\left.\mathrm{N}, 153^{\circ} \mathrm{E}\right)$ and “Tango" $\left(29^{\circ} \mathrm{N}, 135^{\circ} \mathrm{E}\right)$ are treated. "Normal" monthly values, which will be the basis of future investigations, are prepared of some of oceanographic elements. Characteristics of the annual variations in the oceanographic elements are discussed, comparison being made between the two sea regions of the Ocean Weather Stations "Extra" and "Tango". Some descriptions are given of spring layers of temperature, chlorinity, and $\sigma_{t}$ and of vertical stability. Besides, numerical values of eddy conductivity are computed by applying FJELDSTAD's method and some relationships between transparency and colour of the sea are examined.
\end{abstract}

\section{Preface}

We have never heard that in former times long-successive observations of meteorological or oceanographic conditions were performed at a station in the middle of an ocean. Recently, many ocean weather stations have been established in the North Pacific and North Atlantic Oceans, where meteorological and aerological routine observations and at times oceanographic surveys also are carried on. The observation on board stationary weather ships provides not only useful information for practical purposes such as sailing, air navigation, weather forecasting, etc., but also valuable data for scientific investigations of oceanographic conditions, their variations, the relations between ocean and atmosphere, and the problem of secular variation of climate. It is of great benefit also to marine meteorology, oceanography and climatology, in that it provides a great number of observational data for remote regions of the ocean where informations have so far been scanty.

On the seas adjacent to Japan, there are two ocean weather stations which are being operated by Japan; namely the O.W.S. "Extra" or "X" (formerly called "X-Ray"; to be denoted by St. "X" hereafter) situated at the position of $39^{\circ} \mathrm{N}, 153^{\circ} \mathrm{E}$ and the O.W.S. "Tango" or " $\mathrm{T}$ " (formerly called "Tare"; henceforth to be denoted by St. " $\mathrm{T}$ ”) situated at $29^{\circ} \mathrm{N}, 135^{\circ} \mathrm{E}$. St. "X" was established in October 1947, and the observation was continued without interruption 
until November 1953, when it was put into suspension on account of some inevitable circumstances. St. " $T$ ", where the weather observations are very useful for predicting the course of typhoons, was established in September 1948, and at present the ocean weather ships are being engaged in observation only during the summer season (May to November) when typhoons so frequently pass through Japan or its neighbourhood. During the period of May 1950 to November 1953, the observations were performed there without interruption.

At both stations " $\mathrm{X}$ " and “ $\mathrm{T}$ ”, oceanographic observations are carried out more than 10 times a month, on an average, during the period now under investigation. Temperature-measurement and water sampling extend mostly to considerable depths and, at times, to very great depths. The present author has not heard of observations of temperature, chlorinity, etc. in a limited area in the ocean, extending to considerable depths and over such a long period as a few years except for Sts. " $X$ " and “ $T$ ".

Oceanographic conditions in the sea region off the eastern coast of Tohoku (Tōhoku means " northeast") District have a great influence upon weather conditions over that District and consequently upon the rice-crop there, about which the nation has a deep concern. It is an earnest desire of the nation that prediction of oceanographic conditions become possible, for even if it may be confined to the Tohoku Sea Region, it will be of great benefit to the nation at large.

The present author intends to investigate the variations of oceanographic conditions and the influences of meteorological conditions upon them, mainly using the data of observation taken on board the ocean weather ships. He will be happy if these investigations can contribute something to the establishment of the method for predicting oceanographic conditions.

\section{2. "Normal" values of some oceanographic elements}

Among the oceanographic data which were obtained at St. " $\mathrm{X}$ " during the period from March 1948 to November 1953 (Before March 1948 oceanographic observations were made only a few times in October November 1947), only the data of water temperature, chlorinity, $\sigma_{t}$ (derived from the preceding two elements), transparency, and colour of the sea are treated in the present paper. The observations made within the area of $2^{\circ}$ square centered at the position of $39^{\circ} \mathrm{N}, 153^{\circ} \mathrm{E}$ are all taken into account. As for the distribution of oceanographic stations within the said area, about 90 percent of the total stations are included within $1^{\circ}$ square centered at the same point and 80 percent or so are distributed within $40^{\prime}$ square. On dealing with the data, however, attention is paid only to whether the stations lie within the $2^{\circ}$ square or not, and not to the manner they are distributed within the limited area; namely, the observations are equally treated without any discrimination so long as they are made in the limited area. This indiscrimination of the positions of observation will be permitted when the average conditions in the open sea so remote from any continent are under consideration.

The numbers of oceanographic stations in the St. " $X$ " area are entered in Table 1. The stations where the Nansen bottle reached the depth greater than $1000 \mathrm{~m}$ and $1500 \mathrm{~m}$ are respectively about 50 percent and 30 percent in number of the grand total. In 1948 and 1949, the observations at depths greater than 300 $\mathrm{m}$ were not yet so frequently made, on account of the insufficiency of equipments. 
Table 1. Items of Numbers of Oceanographic Observation in the Station "X" $\left(39^{\circ} \mathrm{N}, 153^{\circ} \mathrm{E}\right)$ Area during the Period from March 1948 to November 1953.

\begin{tabular}{r|rrrrrrrrrrrrrrr}
\hline \hline & Jan. & Feb. Mar. Apr. May & June & July & Aug. Sept. Oct. Nov. Dec. & Year \\
\hline 1948 & - & - & 6 & 6 & 19 & 9 & 19 & 11 & 18 & 3 & 12 & 9 & 112 \\
1949 & 9 & 9 & 5 & 8 & 14 & 20 & 17 & 21 & 17 & 15 & 11 & 5 & 151 \\
1950 & 8 & 5 & 13 & 11 & 18 & 16 & 17 & 22 & 13 & 16 & 12 & 7 & 158 \\
1951 & 6 & 8 & 15 & 13 & 15 & 17 & 17 & 18 & 12 & 14 & 14 & 14 & 163 \\
1952 & 7 & 8 & 9 & 13 & 12 & 17 & 18 & 15 & 14 & 13 & 12 & 11 & 149 \\
1953 & 8 & 10 & 9 & 12 & 15 & 17 & 16 & 14 & 5 & 6 & 4 & - & 116 \\
\hline Sum & 38 & 40 & 57 & 63 & 93 & 96 & 104 & 101 & 79 & 67 & 65 & 46 & 849 \\
\hline
\end{tabular}

Subsurface temperatures were measured by means of reversing thermometers attached to Nansen bottles. The sea-surface temperature was measured with an ordinary thermometer and a canvas bucket. Chlorinity was determined by KNUDSEN's method of titration. The transparency was measured by a Secchi disc with a diameter of $30 \mathrm{~cm}$ and the colour of the sea was observed according to the "Forel scale".

The depth of sampling was obtaind, as a rule, from the corrected reading of the unprotected reversing thermometer and the water temperature in situ, but when the sampling was made at small depths (generally less than $100 \mathrm{~m}$ ), the wire angle was relied on. The thermometric depths were more or less corrected by the graphical method (depth difference method) proposed by Pollak [1], and the depths of sampling between them at which unprotected thermometer was not used were interpolated by the same method.

Temperature and chlorinity for the standard levels were obtained by linear interpolation from the values for the accepted depths. Then, monthly means of temperature and chlorinity for the standard levels were computed. Also, those of the transparency and colour of the sea were obtained. Lastly, the "normal" values of each element for each month of the year were determined from these monthly means during the years under investigation. These "normal" values are, of course, only temporary ones, but they will be used as the basis of discussions in this and subsequent papers. Table 2 contains the "normal" values of the temperature, chloriniy, $\sigma_{t}$, transparency, and colour of the sea for St. "X".

The "normal" values of the same elements for St. " $T$ " (not tabulated here) have become available thanks to the members of the Oceanographical Section, the Central Meteorological Observatory. The data of St. "T" from which the "normal" values were computed are those obtained during the period from September 1948 till November 1953, but during the periods from December 1948 to May 1949 and from December 1949 to May 1950, no ocean weather ship was at work at St. " $\mathrm{T}$ " and accordingly no data are available for these periods.

\section{Oceanographic circumstances of Sts. " $\mathrm{X}$ " and " $\mathrm{T}$ "}

The oceanographic surroundings of Sts. " $\mathrm{X}$ " and " $\mathrm{T}$ ", viz. how these stations are situated with regard to ocean current and oceanic front, will be easily understood from Fig. 1, which is originally due to UDA [2] and in which the positions of Sts. " $\mathrm{X}$ " and " $\mathrm{T}$ " are inserted, though the current systems in the figure 
Table 2. "Normal" Values of Oceanographic Elements for St. "X" $\left(39^{\circ} \mathrm{N}, 153^{\circ} \mathrm{E}\right)$ (Based upon the Data of Observation during the Period from Mar. 1948 to Nov. 1953).

\begin{tabular}{|c|c|c|c|c|c|c|c|c|c|c|c|c|c|}
\hline & Jan. & Feb. & Mar. & Apr. & May & June & July & Aug. & Sept. & Oct. & Nov. & Dec. & Year \\
\hline Depth (m) & \multicolumn{12}{|c|}{ A. Water Temperature $\left(T^{\circ} \mathrm{C}\right)$} & \\
\hline & 13.37 & 11.73 & 10.59 & 11.82 & 13.88 & 17.40 & 20.77 & 24.28 & 23.38 & 19.93 & & & 16.65 \\
\hline 10 & & 11.87 & 10.64 & 11.71 & 13.78 & 17.12 & & 23.98 & & & & & \\
\hline 25 & 13.44 & 11.88 & 10.61 & 11.62 & 13.46 & 16.16 & 18.49 & 21.40 & 22.68 & 19.86 & & & \\
\hline 50 & 13.34 & 11.82 & 10.52 & 11.40 & 12.77 & 14.08 & 15.07 & 16.14 & 16.89 & 17.95 & & 15.13 & 14.37 \\
\hline 75 & 13.23 & 11.70 & 10.33 & 11.06 & 12.09 & 12.79 & 13.43 & 13.83 & 14.14 & 14.99 & 16.56 & & 13.26 \\
\hline 100 & .08 & 11.62 & 10.19 & 10.78 & 11.42 & & & 12.49 & 12.72 & & & & \\
\hline & .60 & 11.15 & 9.78 & 10.18 & 10.36 & 10.42 & & 10.53 & 10 & & & & \\
\hline 200 & 11.44 & 10.39 & 9.04 & 9.27 & 9.42 & 9.44 & & 9.09 & 9. & & & & 9.76 \\
\hline 300 & 8.87 & 8.23 & 7.11 & 7.15 & 7.57 & 7.93 & 6.86 & 6.65 & 6.72 & 7.17 & & 7.65 & 7.44 \\
\hline 400 & 6.74 & 6.54 & 5.14 & & 5.66 & 5.76 & & 5.28 & 5.42 & & & & \\
\hline 500 & 5.24 & 5.14 & 4.42 & 4.54 & 4.72 & 4.74 & 65 & 4.53 & 4. & & & & 4.73 \\
\hline 600 & 4.48 & 4.47 & 4.12 & 4.19 & 4.22 & 4.26 & 4.22 & 4.21 & 4.2 & 10 & & & 4.25 \\
\hline 800 & 3.73 & 3.74 & 3.55 & 3.58 & 3.60 & 3.65 & 3.58 & 3.61 & 3.63 & 3.61 & 3.54 & 65 & 3.62 \\
\hline 1000 & .22 & 3.22 & 3.07 & 3.09 & 3.12 & 3.14 & 3.08 & 3.11 & 3.16 & & & & 3.13 \\
\hline 1200 & 2.80 & 2.80 & 2.70 & 2.74 & 2.74 & 2.77 & 2.72 & 2.72 & 2.74 & & 2.70 & & 2.75 \\
\hline \multirow[t]{2}{*}{1500} & 2.41 & 2.38 & 2.34 & 2.37 & 2.35 & 2.35 & 2.32 & 2.36 & 2.36 & 2.38 & 2.34 & 2.39 & 2.36 \\
\hline & \multicolumn{12}{|c|}{ B. Chlorinity $(\mathrm{Cl} \%)$} & \\
\hline 0 & 19.06 & 19.05 & 19.02 & 19.06 & 19.10 & 19.02 & 18.95 & i 8.88 & 18.86 & 18.92 & & & $18.99_{2}$ \\
\hline 10 & .05 & 19.03 & 18.99 & 19.04 & 19.06 & 02 & & 18.87 & 18.84 & 18. & & & 18.973 \\
\hline 25 & .04 & 19.02 & 18.99 & 19.03 & 19.06 & 19.03 & & 18.93 & 18.88 & 18.90 & & & \\
\hline 50 & 19.04 & 19.02 & 18.98 & 19.03 & 19.05 & 19 & & 19.04 & 19.05 & 18.98 & & & \\
\hline 75 & 19.03 & 19.02 & 18.97 & 19.01 & 19.03 & 19.04 & 39.06 & 19.04 & 19.07 & 19.06 & & & \\
\hline 100 & .01 & 19.01 & 18.96 & 19.00 & 19.01 & 19.00 & & 19.02 & 19.04 & & & & \\
\hline 150 & .01 & 18.99 & 18.94 & 18.96 & 18.96 & 18.93 & 18.97 & 18.94 & 18.97 & 18.98 & 19.02 & & $18.97_{3}$ \\
\hline 200 & 18.99 & 18.95 & 18.90 & 18.92 & 18.93 & 18.89 & 18.90 & 18.88 & 18.91 & 18.91 & & & $18.92_{4}$ \\
\hline 300 & 18.89 & 18.88 & 18.82 & 18.83 & 18.84 & 18.85 & 18.80 & 18.80 & 18.80 & 18.83 & 18.83 & 18.8 & $.83_{6}$ \\
\hline & & & 18.78 & 18.80 & 18.81 & 18.79 & & 18.78 & 18.79 & & & & \\
\hline 00 & & 84 & 18.83 & 18.84 & 18.83 & 18.80 & & 18.82 & 18.82 & 18.81 & & & 18.828 \\
\hline 600 & 18.87 & 18.87 & 18.89 & 18.89 & 18.88 & 18.86 & 18.89 & 18.88 & 18.88 & 18.88 & 18 & 18 & $18.88_{2}$ \\
\hline 800 & 18.96 & 18.96 & 18.98 & 18.98 & 18.98 & 18.95 & 18.97 & 18.98 & 18.97 & 18.97 & 18.98 & 18.97 & $18.97_{1}$ \\
\hline 00 & & & & & 19.03 & .01 & & & & 19. & & & \\
\hline & & & 19.07 & 19.07 & 19.07 & 19.05 & & & & & & & 19 \\
\hline \multirow[t]{2}{*}{1500} & & & & & 19.11 & 19.08 & 19 & & & 19.11 & & & \\
\hline & \multicolumn{12}{|c|}{ C. Density $\left(\sigma_{t}\right)$} & \\
\hline 0 & & & 26.37 & 26.21 & 25.85 & & & & & & & & 25. \\
\hline 10 & & & & & 25.81 & 1 & & & & & & & \\
\hline 25 & .85 & 26.14 & 26.33 & 26.21 & 25.88 & 25.25 & 24.65 & 23.80 & 23.37 & 24.17 & & & \\
\hline 50 & 25.88 & 26.15 & 26.33 & 26.24 & 26.00 & 25.73 & & 25.27 & 25.11 & 24.76 & & & 25.64 \\
\hline 75 & 25.88 & 26.17 & 26.35 & 26.28 & 26.12 & 25.99 & 25.88 & 25.77 & 25.75 & 25.56 & 25.13 & 25.41 & 25.87 \\
\hline & & .18 & 26.35 & 26.31 & 26.21 & 26.11 & & & & & & & 26.02 \\
\hline & & 26.23 & 26.40 & 26.35 & 26.33 & 26.27 & & 26.27 & 26 & & & & \\
\hline 200 & 26.18 & 26.31 & 26.47 & 26.45 & 26.44 & 26. & 26 & 26.43 & 26.43 & 26.38 & & & 26.38 \\
\hline 300 & 26.48 & 26.56 & 26.64 & 26.65 & 26.60 & 26.56 & 26.65 & 26.67 & 26.66 & 26.65 & 26.63 & 26.6 & 26.62 \\
\hline & .72 & 26.75 & 26.83 & & 26.81 & 26.77 & & & & & & & \\
\hline 00 & .89 & 26.92 & 26.98 & 26.98 & 26.95 & 26.90 & 26.96 & 26.95 & 26. & 26.93 & & & \\
\hline 600 & 27.03 & & 27.10 & 27.09 & 27.07 & 27.04 & & 27.07 & 27.07 & 27.09 & & & 27.07 \\
\hline 800 & 27.24 & 27.24 & 27.29 & 27.28 & 27.28 & & & 27.28 & 27.26 & 27.27 & 27.29 & 27.26 & 27.25 \\
\hline & & & & & & & & & & & & & 27.40 \\
\hline 1200 & 27.49 & 27.49 & 27.50 & 27.49 & 27.49 & 27.46 & 27.48 & 27.48 & 27.51 & 27.49 & & & 27.49 \\
\hline \multirow[t]{2}{*}{1500} & 27.58 & 27.58 & 27.58 & 27.60 & 27.58 & 27.54 & 27.57 & 27.58 & 27.58 & 27.58 & 27.62 & 27.60 & 27.59 \\
\hline & \multicolumn{12}{|c|}{ Transparency $(D \mathrm{~m})$ and Colour of the Sea $(F)$} & \\
\hline$D$ & 23.8 & 24.4 & 21.9 & 17.2 & 15.8 & 16.8 & 23.0 & 27.4 & 26.1 & 22.6 & 20.9 & 22. & 21.9 \\
\hline$F$ & 3.2 & 2.9 & 3.0 & 3.3 & 3.6 & 3.1 & 2.7 & 2.2 & 2.6 & 3.0 & 3.1 & 2.9 & 3.0 \\
\hline
\end{tabular}


may represent a pattern more or less different from the average or normal one. St. "X" lies in the northwestern Pacific Ocean about $1000 \mathrm{~km}$ east of the Tōhoku District of Japan. The subarctic convergence or front lies near the $42^{\circ} \mathrm{N}$ parallel of latitude, to the north of which the Subarctic Water mass is encountered. And to the south of $36^{\circ} \mathrm{N}$, where a sharp transition in water mass takes places, the major branch of the Kuroshio Extension runs toward due east. Again, in the region including St. " $X$ ", that is between latitudes $36^{\circ} \mathrm{N}$ and $42^{\circ} \mathrm{N}$, extends a water mass of Kuroshio origin, but this water mass is much diluted by mixing with the Oyashio or the Subarctic Water.

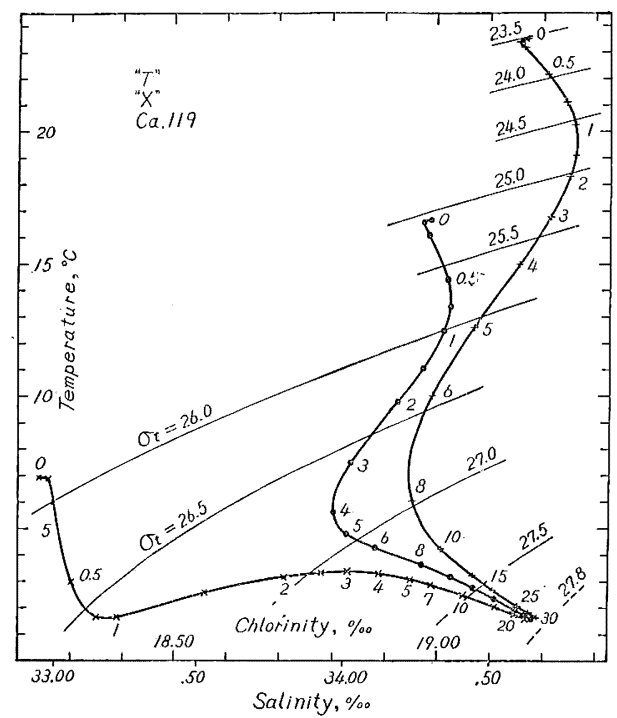

Fig. 2. Temperature-chlorinity (salinity) relations at St. " $\mathrm{X}$ ", St. " $\mathrm{T}$ ", and Carnegie station 119 ( Ca. 119). Depths in hectometers are entered along the curves. Locations of the stations are in Fig. 1 .

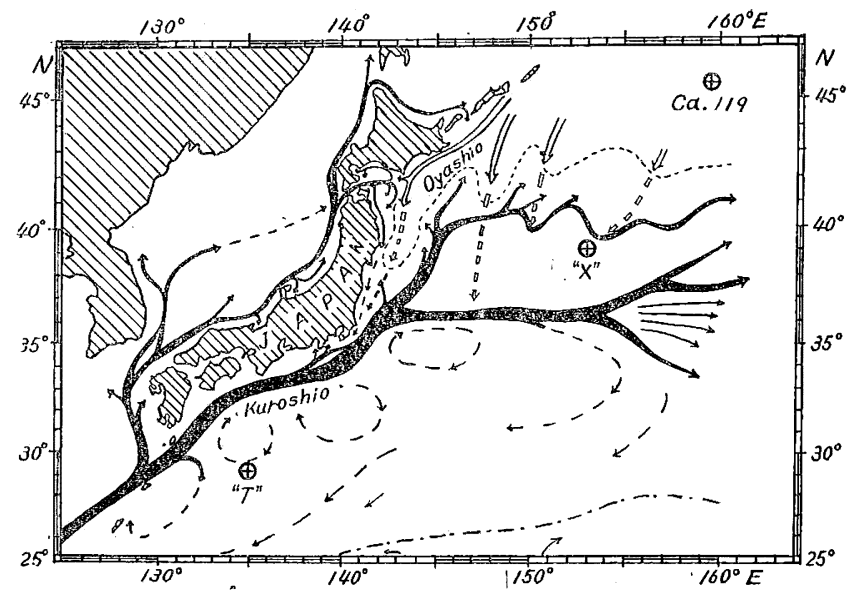

Fig. 1. Current systems in the sea adjacent to Japan (after UDA [2] ; based on the oceanographic surveys made in summer 1933) and the locations of St. "Extra" ("X"; $39^{\circ} \mathrm{N}, 153^{\circ} \mathrm{E}$ ), St. "Tango" ("T"; $29^{\circ} \mathrm{N}, 135^{\circ} \mathrm{E}$ ), and Carnegie station 119 (Ca. 119; $\left.45^{\circ} 24^{\prime} \mathrm{N}, 159^{\circ} 36^{\prime} \mathrm{E}\right)$.

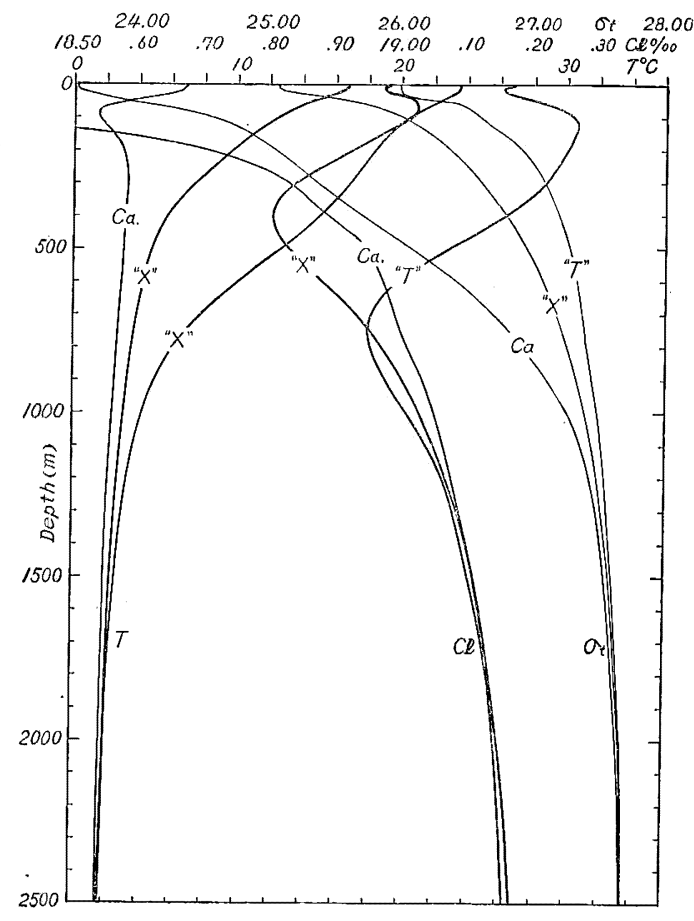

Fig. 3. Vertical distributions of "temperature, chlorinity, and $\sigma_{t}$ at St. "X", St. "T", and Carnegie station 119 (Ca 119). 
St. “T”, situated at a point about $500 \mathrm{~km}$ off the Cape Shionomisaki, lies in the region of a rather small-scale counter-current at a considerable distance from the main flow of the Kuroshio. The characteristics of the water masses at Sts. "X" and " $T$ " will be illustrated in terms of the $T$ - $C l$ curves in Fig. 2 or the vertical distribution of each element shown in Fig. 3. In these figures, the data for Carnegie station 119 (located at $45^{\circ} 24^{\prime} \mathrm{N}, 159^{\circ} 36^{\prime} \mathrm{E}$; observed on July 7, 1929. FLEMING and others [3]), whose position is entered in Fig. 1, are also plotted for comparison. The $\mathrm{T}-\mathrm{Cl}$ curve for St. " $\mathrm{T}$ " is nearly the same as the one to be obtained in the region of the Kuroshio Current. The T-Cl curve for Carnegie station 119 is of the same type as that for the Subarctic Water mass. As seen from Figs. 2 and 3, the water at St. " $\mathrm{X}$ " is rather closer to the Kuroshio Water, but with lower temperature and lower chlorinity due to admixture with the Subarctic Water. The Intermediate Water which represents the Subarctic Water having crept into an intermediate layer below the sea surface is characterized by a chlorinity minimum in chlorinity-depth curve. Below the mixed water (St. "X"), the chlorinity minimum is found at a depth of about $400 \mathrm{~m}$ with a value of about $18.80 \%$. Below the Kuroshio Water (St. "T"), it occurs at a depth between $600 \mathrm{~m}$ and $800 \mathrm{~m}$, its value being about $18.95 \%$. Within the Subarctic Water region (Carnegie station 119), no chlorinity minimum layer is present.

The situation of the subarctic front and the courses of the ocean currents are not always stationary, but they change due to various causes, so that the region of St. "X" is occupied at times by water rich in Subarctic Water or by water rich in Kuroshio Water. Therefore, it can be foreseen that the oceanographic conditions at St. " $\mathrm{X}$ " will present intense and complicated fluctuations.

\section{The annual variations of temperature and chlorinity}

Oceanographic data which are available for discussion of the annual variation of temperature as well as chlorinity at subsurface depths have so far been scanty. The data for Sts. " $\mathrm{X}$ " and "T", covering several years, are very valuable in this respect.

It is desirable to characterize the annual variation by some basic parameters besides by the normal monthly values themselves. For this purpose, harmonic analysis is available. Representing an oceanographic element by $f$, the expansion in Fourier series of $f$ gives

$$
f=A_{0}+A_{1} \cos \left(\theta-\alpha_{1}\right)+A_{2} \cos \left(2 \theta-\alpha_{2}\right)+A_{3} \cos \left(3 \theta-\alpha_{3}\right)+\cdots \cdots,
$$

where $A_{0}$ denotes the annual mean value of $f, A_{1}$ the amplitude of the annual component, $A_{2}$ the amplitude of the semi-annual component, and so on; $\theta$ represents the phase angle, and $\alpha_{1}, \alpha_{2}, \ldots \ldots$ are the phase lags of the respective harmonic components. The correspondence between $\theta$ and the monthly values is chosen as follows :

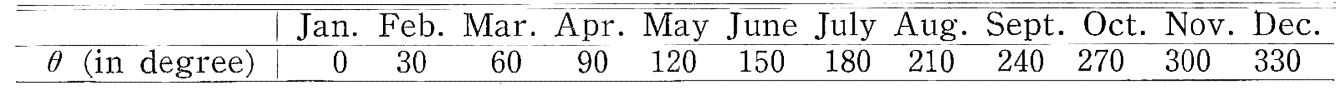

The origin of $\theta$ is placed at the mid-point of January, since the monthly values relate to the mid-point of the month.

Harmonic constants of the annual variations of temperature and chlorinity at St. "X" are tabulated for different depths between the surface and $300 \mathrm{~m}$ (Table 
Table 3. Harmonic Constants of the Annual Variations in Temperature and Chlorinity.

(a) Station “ $\mathrm{X}$ " $\left(39^{\circ} \mathrm{N}, 153^{\circ} \mathrm{E}\right)$

\begin{tabular}{|c|c|c|c|c|c|c|c|c|}
\hline \multicolumn{9}{|c|}{ Temperature } \\
\hline $\begin{array}{c}\text { Depth } \\
(\mathrm{m})\end{array}$ & $A_{0}$ & $A_{1}$ & $\alpha_{1}$ & $A_{2}$ & $\alpha_{2}$ & $100\left(\frac{A_{2}}{A_{1}}\right)$ & $\Delta$ & $R$ \\
\hline & 0 & 0 & 0 & $\circ$ & $\circ$ & $\%$ & $\circ$ & \\
\hline 0 & 16.65 & 6.17 & 228 & 1.09 & 53 & 18 & +21 & 0.40 \\
\hline 10 & $16.6 !$ & 6.06 & 230 & 1.06 & 54 & 17 & +22 & 0.37 \\
\hline 25 & 16.04 & 5.36 & 236 & 0.60 & 79 & 11 & +16 & 0.41 \\
\hline 50 & 14.37 & 3.25 & 254 & 0.60 & 252 & 18 & -52 & 0.22 \\
\hline 75 & 13.26 & 2.21 & 271 & 0.94 & 277 & 43 & -47 & 0.27 \\
\hline 100 & 12.43 & 1.62 & 286 & 0.87 & 293 & 54 & -40 & 0.17 \\
\hline 150 & 11.02 & 0.97 & 317 & 0.58 & 316 & 60 & -21 & 0.22 \\
\hline 200 & 9.76 & 0.75 & 344 & $(0.48)$ & $(330)$ & $(64)$ & $(-1)$ & $(0.28)$ \\
\hline 300 & 7.44 & $(0.60)$ & (25) & $(0.46)$ & $(327)$ & $(77)$ & $(+41)$ & $(0.34)$ \\
\hline \multicolumn{9}{|c|}{ Chlorinity } \\
\hline 0 & $\begin{array}{r}\% \\
18.99\end{array}$ & $\begin{array}{r}\% \\
0.09\end{array}$ & $\begin{array}{r}0 \\
61\end{array}$ & $\begin{array}{r}\% 0 \\
0.04\end{array}$ & $\begin{array}{r}\circ \\
276\end{array}$ & $\begin{array}{l}\% \\
44\end{array}$ & $\begin{array}{r}0 \\
-77\end{array}$ & $\begin{array}{r}\% \\
0.015\end{array}$ \\
\hline 10 & 18.97 & 0.09 & 62 & 0.05 & 288 & 56 & -82 & $0.01_{4}$ \\
\hline 25 & 18.98 & 0.07 & 80 & 0.04 & 309 & 57 & -74 & $0.0 \mathrm{i}_{4}$ \\
\hline 50 & 19.02 & 0.04 & 155 & 0.02 & 25 & 50 & -37 & $0.022_{0}$ \\
\hline 75 & 19.02 & 0.03 & 207 & $(0.01)$ & (86) & (33) & $(-16)$ & $\left(0.02_{4}\right)$ \\
\hline 100 & 19.01 & 0.03 & 247 & $(0.01)$ & $(211)$ & (33) & $(-39)$ & $\left(0.0 \mathrm{i}_{7}\right)$ \\
\hline 150 & 18.97 & 0.03 & 326 & $(0.01)$ & (293) & (33) & $(0)$ & $\left(0.01_{4}\right)$ \\
\hline 200 & 18.92 & 0.03 & 352 & $(0.01)$ & (294) & (33) & $(+25)$ & $\left(0.01_{4}\right)$ \\
\hline 300 & 18.84 & 0.03 & 19 & $(0.02)$ & $(320)$ & $(67)$ & $(+39)$ & $\left(0.01_{4}\right)$ \\
\hline
\end{tabular}

(b) Station " $\mathrm{T}$ ” $\left(29^{\circ} \mathrm{N}, 135^{\circ} \mathrm{E}\right)$

\begin{tabular}{|c|c|c|c|c|c|c|c|c|}
\hline \multicolumn{9}{|c|}{ Temperature } \\
\hline $\begin{array}{l}\text { Depth } \\
\text { (m) }\end{array}$ & $A_{0}$ & $A_{1}$ & $\alpha_{1}$ & $A_{2}$ & $\alpha_{2}$ & $100\left(\frac{A_{2}}{A_{1}}\right)$ & $\Delta$ & $R$ \\
\hline & 0 & & 0 & 0 & 0 & $\%$ & 0 & 0 \\
\hline 0 & 23.49 & 4.58 & 221 & 0.51 & 88 & $\begin{array}{l}70 \\
11\end{array}$ & -3 & 0.14 \\
\hline 10 & 23.40 & 4.46 & 223 & 0.44 & 92 & 10 & -3 & 0.14 \\
\hline 25 & 23.18 & 4.22 & 226 & 0.45 & 115 & 11 & -12 & 0.13 \\
\hline 50 & 22.15 & 2.90 & 240 & 0.79 & 191 & 27 & -36 & 0.23 \\
\hline 75 & 21.12 & 1.65 & 251 & 0.69 & 227 & 42 & -43 & 0.25 \\
\hline 100 & 20.26 & 0.83 & 254 & 0.41 & 242 & 49 & -47 & 0.18 \\
\hline \multicolumn{9}{|c|}{ Chlorinity } \\
\hline & $\%$ & $\%$ & 0 & $\%$ & $\circ$ & $\%$ & 0 & $\%$ \\
\hline 0 & 19. 17 & 0.14 & 42 & 0.04 & 182 & $\begin{array}{l}70 \\
29\end{array}$ & -49 & 0.017 \\
\hline 10 & 19.15 & 0.14 & 44 & 0.04 & 178 & 29 & -45 & $0.02_{1}$ \\
\hline 25 & 19.16 & 0.12 & 51 & 0.03 & 188 & 25 & -43 & $0.01_{4}$ \\
\hline 50 & 19.21 & 0.07 & 83 & 0.01 & 101 & 14 & +32 & $0.00_{6}$ \\
\hline 75 & 19.24 & 0.05 & 121 & $(0.02)$ & $(116)$ & $(40)$ & $(+63)$ & $\left(0.01_{2}\right)$ \\
\hline 100 & 19.26 & 0.02 & 143 & $(0.01)$ & $(150)$ & (50) & $(+68)$ & $\left(0.00_{7}\right)$ \\
\hline
\end{tabular}


$3(\mathrm{a}))$. Table $3(\mathrm{~b})$ is prepared for St. " $\mathrm{T}$ ". The ter-annual component and the higher harmonics, being generally small in amplitude, seem less important, and so their values are not tabulated here. The values shown in parentheses are related to those for which the significance of 95 percent probability has been denied. The ratio $A_{2} / A_{1}$ may be regarded as a measure of the degree of skewness of the annual variation curve from pure cosine curve. The symbol $\Delta$ represents the phase difference; $\Delta=\alpha_{1}-\left(\frac{\alpha_{2}}{2}+180\right)$. The meaning of the value of $\Delta$ may be explained as follows. When $\Delta$ is equal to zero, the maxima of the two components (annual and semi-annual) occur simultaneously; the curve of annual variation becomes completely symmetric. When $\Delta>0$, the time of maximum in the annual variation is brought forward and the time of minimum is set back. Therefore, the time interval between minimum and maximum for increasing value is less than the time interval for decreasing value. When $\Delta<0$, the time of maximum is set back and the time of minimum is brought forward. Therefore, the time interval for increasing value is greater than the time interval for decreasing value. The function $R=\sqrt{\frac{1}{12}} \sum_{n=1}^{12}\left\{\left(f_{n}\right)_{N}-\left(f_{n}\right)_{c}\right\}^{2}$ where $\left(f_{n}\right)_{N}$ represents the "normal" value of an element for the $n$th month of the year and $\left(f_{n}\right)_{c}$ the value of the same element for the $n$th month calculated from the harmonic constants, may be regarded as a measure representing the degree of fitness of the calculated curve to the "normal" one.

The main features and regional peculiarities of the annual variations of temperature and chlorinity will be illustrated by means of figures and tables.

(i) Annual variation of sea water temperature.

The physical factors determining the variation of temperature at subsurface depths are (1) the amount of heat that is directly absorbed at different depths, (2) the effect of heat conduction, (3) the currents related to lateral displacement of water masses, and (4) the effect of vertical motion.

Judging from the courses of curves in Fig. 4a, it may be concluded that at St. " $X$ " the annual variation due to heating and cooling near the surface is transmitted down to a depth of more than $200 \mathrm{~m}$ by the process of heat conduction. The minimum temperature occurs at all depths between the surface and $200 \mathrm{~m}$ in March. Since then the tẻmperatures at given depths increase steadily-rapidly near the surface and less so in lower layers-up to their respective maximum values. The time of the maximum temperature occurs later with increasing depth, in such a manner as shown by a thin line in the somewhat schematic isopleth in Fig. 5a. And according to the resultant curves of annual and semiannual harmonic waves, the maximum temperature occurs at the surface and at the depth of $10 \mathrm{~m}$ almost coincidentally at the end of August, and at the depths of $50 \mathrm{~m}, 100 \mathrm{~m}$, and $200 \mathrm{~m}$ in mid-October, at the end of November, and at the end of January, respectively. In autumn, an isothermal layer begins to be formed due to the vertical convection of water. Then it grows with the march of season, and in late winter it attains its maximum thickness. It is noted that the temperature at the surface is, on an average, somewhat $\left(0.1^{\circ} \mathrm{C}\right.$ or so) lower than that at the depth of $10 \mathrm{~m}$ during the period from October to March. This may be attributed to the intense cooling by cold air and to the large loss of heat by evaporation.

The annual variation of temperature at St. " $\mathrm{T}$ " (Figs. $4 \mathrm{~b}$ and $5 \mathrm{~b}$ ) is in charac- 

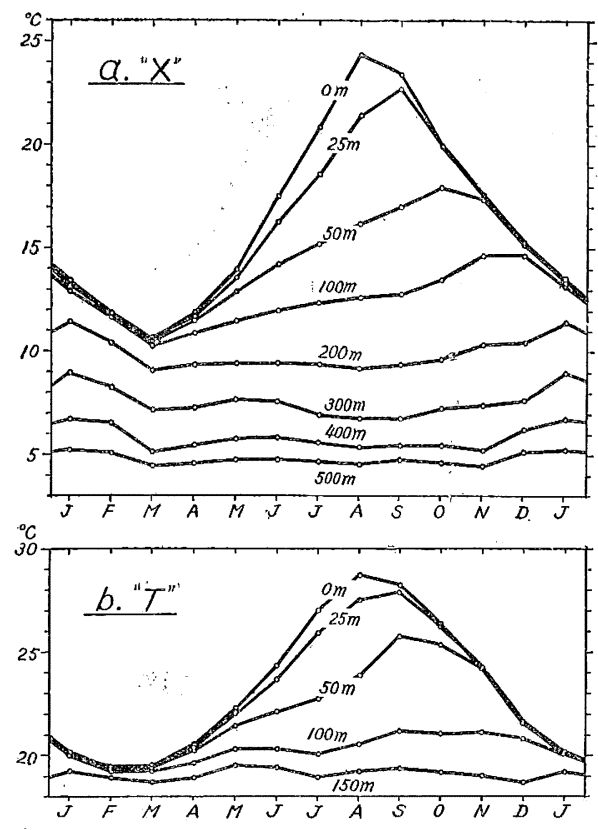

Fig. 4 .

(a) Annual variation of temperature at different depths at St. "X". (b) Corresponding variation at $\mathrm{St}$. " $\mathrm{T}$ ".
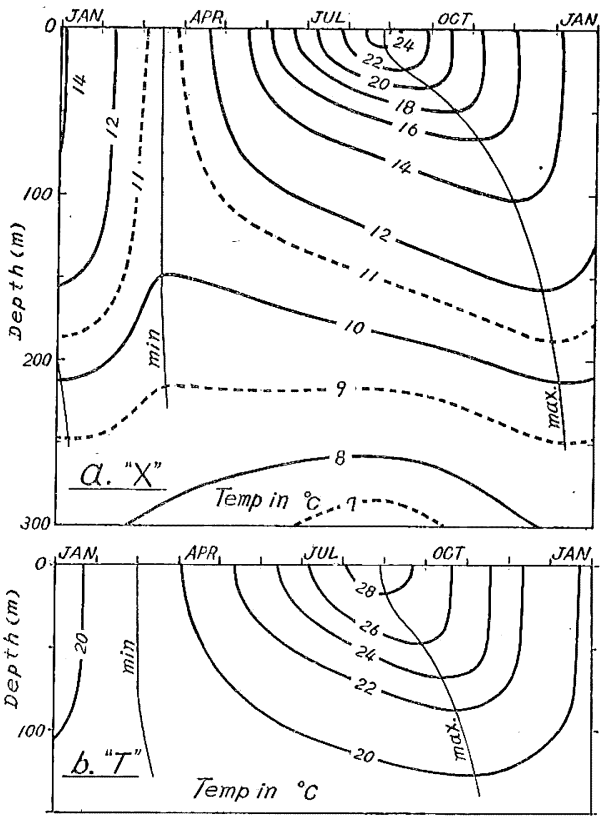

Fig. 5 .

(a) Isopleth diagram of temperature at St. " $\mathrm{X}$ ". (b) Corresponding isopleth diagram at St. "T". These diagrams are somewhat schematically drawn. Thin lines represent the displacement of the times of maximum and minimum temperatures with increasing depth.

ter similar to that at St. "X" in respect to the displacement of the time of maximum with depth, the reduction of the annual range with depth, and the agreement of the times of minima at different depths; there is no essential difference in the character of the annual variation of temperature between Sts. " $X$ " and " $\mathrm{T}$ ". However, it need hardly be said that the annual variations at the two stations have different values of the basic parameters characteristic of the regionality.

As seen in Table 3, a remarkable or abrupt change in the value of every parameter takes place between the layers of $25 \mathrm{~m}$ and $50 \mathrm{~m}$ at both stations. At depths between the surface and $25 \mathrm{~m}$, the value of $A_{2} / A_{1}$ is small at both stations, especially so at St. " $\mathrm{T}$ ". Namely, the annual variation of temperature shows the shape of a curve little distorted from a pure cosine curve, and the annual range is approximately determined by the amplitude of the annual component, $A_{1}$. The function $\Delta$ has small positive values in these depth layers at St. " $X$ ". Therefore the time interval between minimum and maximum for increasing temperature is slightly less than that for decreasing temperature; the time rate of increasing temperature is, on an average, greater than that of decreasing temperature. On the other hand, in the corresponding layers at St. " $\mathrm{T}$ ", $\Delta$ is negative and smaller in absolute value; therefore the time interval for increasing temperature is only slightly longer than that for decreasing temperature, and particularly at the surface and the depth of $10 \mathrm{~m}$ the annual temperature curve is almost symmetrị- 
cal. In the layers lower than $50 \mathrm{~m}$ at both stations, the ratio $A_{2} / A_{1}$ has mostly large values and the function $\Delta$ has generally large negative values. Therefore, the annual variation curves are, in general, distorted to a high degree and the times of the maxima are greatly set back. At St. " $\mathrm{T}$ ", the annual variation becomes hardly perceptible in a layer of $150 \mathrm{~m}$ depth, differing from the case of St. " $X$ ". The state of decrease of the annual range of temperature with increasing depth can be seen from the following numerical values, which were read off from the resultant curves:

\begin{tabular}{l|l|rrrrr}
\hline \hline Depth (m) & & 0 & 25 & 50 & 100 & 200 \\
\hline Annual & St. “ $\mathrm{X}$ ” & 12.8 & 10.8 & 6.9 & 4.3 & 1.8 \\
range $\left({ }^{\circ} \mathrm{C}\right)$ & St. “ $\mathrm{T}$ ” & 9.2 & 8.6 & 6.5 & 2.1 & $\cdots$ \\
\hline
\end{tabular}

The annual range is greater at St. " $\mathrm{X}$ " than at St. " $\mathrm{T}$ " in every layer. In addition, as seen from this table, the reducing rate of the annual range with depth is greater at St. "X" in the upper layers within $50 \mathrm{~m}$, while on the contrary, in the layers lower than $50 \mathrm{~m}$, it is rather smaller at St. "X". The time of the maximum temperature occurs almost simultaneously at the surfaces of the two stations, but with increasing depth it occurs somewhat later at St. " $X$ " than at St. " $\mathrm{T}$ ". The time of the minimum temperature takes place only slightly earlier at St. " $\mathrm{T}$ ".

(ii) Annual variation of chlorinity (Figs. 6 and 7).

The factors affecting the variation of chlorinity in the sea are evaporation, precipitation, eddy diffusion processes, and advection processes.

As might be expected, if the transfer of chlorinity is similar to that of heat, the annual variation of chlorinity has characteristics similar to that of temperature: the displacement of the times of the extreme values and the reduction of the amplitude of the variation with depth. At the sea surface, chlorinity is generally higher in the winter season and lower in the summer season. This type of variation may be interpreted as due to the effect of high evaporation and low precipitation during autumn and winter, and of high precipitation and low evaporation from spring to summer at the stations in question or in the region whence water flows into the station area. But, at St. "X", the chlorinity variation from winter to spring - the presence of the weak minimum in March - seems to result from the alternation of water mass rather than to be due to the combined effects of evaporation and precipitation. At both stations, chlorinity at the sea surface is equal to or somewhat higher (up to $0.04 \%$, on an average $0.02 \%$ ) than that at $10 \mathrm{~m}$ depth. This seems to be due to the effect of evaporation. Contrary to the case of temperature, the annual range of chlorinity variation is larger at St. " $\mathrm{T}$ " than at St. " $\mathrm{X}$ " in the upper layers of $75 \mathrm{~m}$ thickness. In the layers lower than $50 \mathrm{~m}$ depth (at both stations), only the annual component is statistically significant and the significance of the other components of chlorinity is doubtful.

The fact that the annual component of chlorinity variation is still significant in the layers of $300 \mathrm{~m}$ and $400 \mathrm{~m}$ depths at St. " $\mathrm{X}$ " may be associated with a possible variation of the Intermediate Water, even if the periodicity of temperature in the same layers is denied significance. A cyclic change takes place in the property of water at the native place of the Intermediate Water (i.e. high latitudes); namely, in the winter season the freezing leads to the fromation of water 


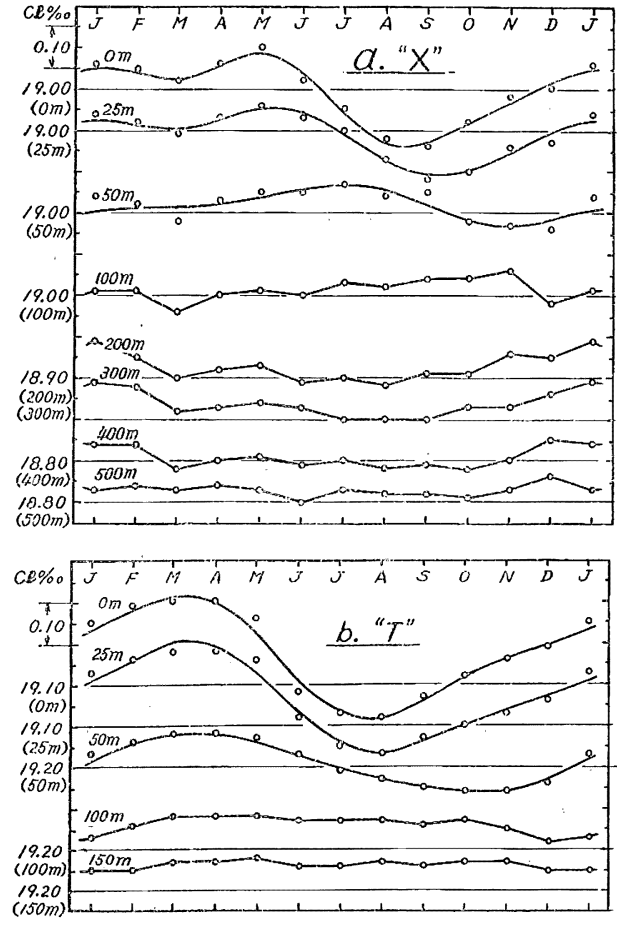

Fig. 6.

(a) Annual variation of chlorinity at different depths at St. "X". (b) Corresponding variation at St. " $\mathrm{T}$ ". Circles represent the "normal" monthly values, and smooth curves are drawn based on the harmonic constants given in Table 3 .

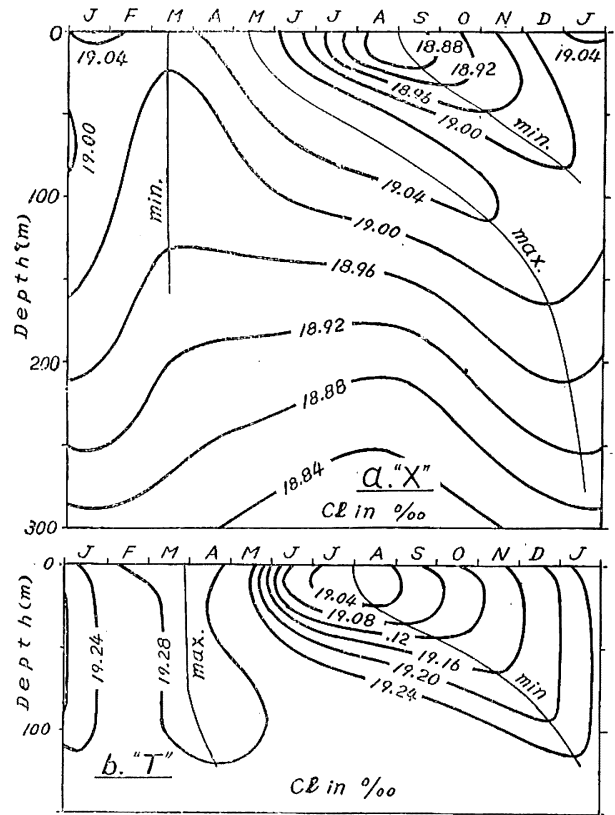

Fig. 7. Somewhat schematic isopleth diagrams of chlorinity at Sts. "X" (a) and " $T$ " (b). Thin lines show the displacement of the times of maximum and minimum chlorinities with increasing depth.

of higher chlorinity and lower temperature (consequently denser water), and in the summer season water of lower chlorinity (less dense water) is formed due to melting of sea ice. And the denser water will creep below the sea surface to an intermediate layer lower than the less dense water. Thus, it is quite possible that the Intermediate Water observed in the southern regions should show in its property and depth a variation with the same period as that at its native place. Such an annual variation of the Intermediate Water seems to have appeared comparatively clearly in 1948 and 1949 (Yamagiwa [4], Koizumi [5]). However, this problem requires further examination.

\section{Spring layer and vertical stability}

The pictures in Fig. 8 show the isopleths of vertical temperature gradient for Sts. " $\mathrm{X}$ " and " $\mathrm{T}$ " respectively which are somewhat schematically drawn. The thin lines in the figures trace the depths of maximum gradient displacing with time. In early summer a fairly distinct thermocline becomes observable in a layer between $25 \mathrm{~m}$ and $50 \mathrm{~m}$ (to speak more precisely, about $30 \mathrm{~m}$ at St. "X" and $40 \mathrm{~m}$ at St. " $\mathrm{T}$ ”). The thermocline, displacing only slightly towards the surface, goes on developing rapidly in intensity till late summer, when it is at the 

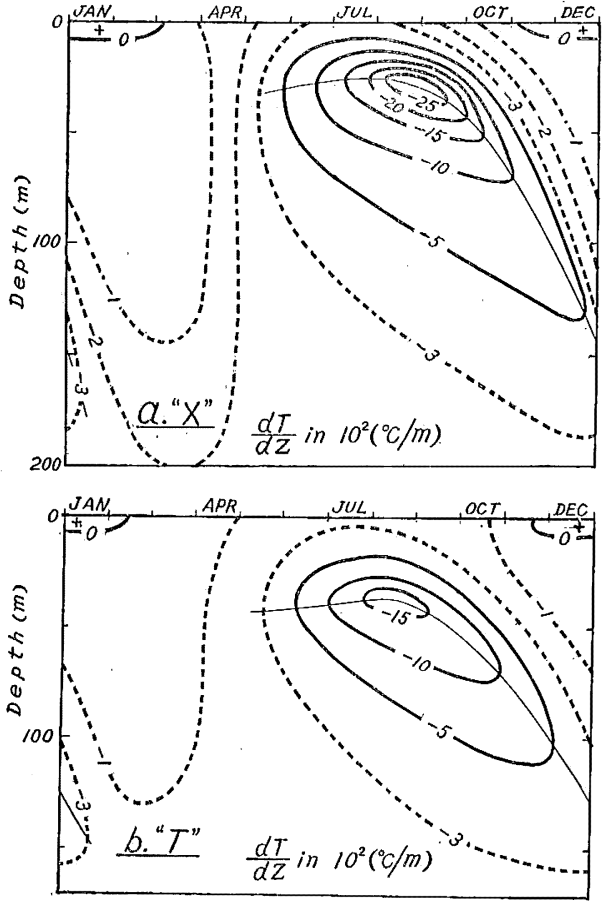

Fig. 8. Isopleth diagrams of verticalytemperature gradient at Sts. "X" (a) and " $T$ " (b). The thin curves trace the depths of maximum gradient displacing with time. extreme both in depth and in intensity (as great as $0.30^{\circ} \mathrm{C} / \mathrm{m}$ averaged between $20 \mathrm{~m}$ and $30 \mathrm{~m}$ depths at St. " $\mathrm{X}$ " and about $0.18^{\circ} \mathrm{C} / \mathrm{m}$ averaged between $30 \mathrm{~m}$ and $40 \mathrm{~m}$ depths at St. "T"). With advance of vertical mixing due to the cooling of sea surface in autumn, the thermocline that has developed to the meridian begins to be destroyed; it becomes less and less in intensity and at the same time moves to greater depth. At last, in late winter or early spring it comes down to the depth (nearly $200 \mathrm{~m}$ at St. " $\mathrm{X}$ " and about $150 \mathrm{~m}$ at St. " $\mathrm{T}$ ”) at which vertical temperature gradient remains nearly constant throughout the year; that is to say, the principal spring layer of temperature disappears.

The isopleth of vertical chlorinity gradient, though it is not inserted here, represents a pattern alike in essence to that of the temperature gradient; especially the seasonal variations in depth of the spring layer of chlorinity and temperature are nearly similar to each other.

As a much greater part of change in $\sigma_{t}$ is, in our case, attributed to change in temperature than to change in chlorinity,

the isopleth of temperature gradient is surmised to have nearly the same features as in the distribution of $\sigma_{t}$ gradient and it has been proved by actual contouring that this surmise is correct. $\sigma_{t}$ gradient can be taken, in upper layers, as a satisfactory measure of vertical stability, and so the picture in Fig. 8 may be regarded as patterns approximately representing the relative distribution of vertical stability. But, in these pictures, the area with positive sign corresponds to "unstable" equilibrium and that with negative sign to "stable" equilibrium. The seasonal variation of the layer of the most stable stratification nearly coincides with that of the principal spring layer of temperature. The vertical stability reaches at St. " $\mathrm{X}$ " (St. " $\mathrm{T}$ ") the meridian of the development of about 8000 (7000). (in $10^{8} \mathrm{E}$ ) between $30 \mathrm{~m}$ and $40 \mathrm{~m}$ in September (August). And in winter and early spring a layer of homogeneous water formed due to vertical convection currents, in which the equilibrium is everywhere nearly indifferent, becomes thicker and thicker, and at St. "X" (St. " $T$ ") it reaches the maximum thickness of $100 \mathrm{~m}$ in March (February).

The result of more exact computations of vertical stability on average conditions is shown in Table 4 , in which the values of vertical gradients of temperature, chlorinity, and $\sigma_{t}$ on average conditions are also shown. The stratification of water is most stable in a layer between $25 \mathrm{~m}$ and $50 \mathrm{~m}$ depths at both stations. Below this layer the vertical stability decreases with increasing depth, but at St. " $T$ ", it is noted, a secondary maximum appears in a layer of about $500 \mathrm{~m}$ depth. 
Table 4. Vertical Gradients of Temperature $\left(T^{\circ} \mathrm{C}\right)$, Chlorinity $(C l \%)$, and $\sigma_{t}$, and Vertical Stability $(E)$.

\begin{tabular}{|c|c|c|c|c|c|c|c|c|}
\hline \multirow[b]{2}{*}{$\begin{array}{c}\text { Depth } \\
(\mathrm{m})\end{array}$} & \multicolumn{2}{|c|}{$10^{5}\left(\frac{d T}{d z}\right)$} & \multicolumn{2}{|c|}{$10^{5}\left(\frac{d C l}{d z}\right)$} & \multicolumn{2}{|c|}{$10^{5}\left(\frac{d \sigma_{t}}{d z}\right)$} & \multicolumn{2}{|c|}{$10^{8} E^{*}$} \\
\hline & "X" & "T " & "X" & "T" & "X" & “ $T "$ & "X" & “ $\mathrm{T} "$ \\
\hline 0 & -400 & -900 & -190 & -190 & -200 & 0 & -200 & 0 \\
\hline 10 & $-3,800$ & $-1,470$ & 73 & 73 & 1,070 & 530 & 967 & 434 \\
\hline 25 & $-6,680$ & $-4,120$ & 144 & 176 & 1,680 & 1,440 & 1,660 & 1,420 \\
\hline 50 & $-4,440$ & $-4,120$ & 16 & 144 & 920 & 1,360 & 900 & 1,300 \\
\hline 75 & $-3,320$ & $-3,440$ & -44 & 72 & 600 & 1,000 & 540 & 940 \\
\hline 100 & $-2,820$ & $-2,360$ & -80 & 2 & 420 & 600 & 400 & 560 \\
\hline 150 & $-2,560$ & $-1,660$ & -98 & -16 & 300 & 400 & 260 & 360 \\
\hline 200 & $-2,320$ & $-1,510$ & -88 & -35 & 240 & 320 & 230 & 280 \\
\hline 300 & $-1,750$ & $-1,780$ & -31 & -50 & 180 & 320 & 170 & 280 \\
\hline 400 & -960 & $-2,390$ & 23 & -88 & 140 & 370 & 130 & 360 \\
\hline 500 & -480 & $-2,560$ & 54 & -76 & 130 & 360 & 110 & 350 \\
\hline 600 & -315 & $-1,970$ & 44 & -20 & 90 & 230 & 75 & 260 \\
\hline 800 & -245 & -920 & 28 & 26 & 75 & 185 & 50 & 135 \\
\hline 1000 & -190 & -445 & 20 & 30 & 45 & 85 & 45 & 90 \\
\hline 1200 & -130 & -230 & 14 & 13 & 33 & 73 & 37 & 43 \\
\hline 1500 & -81 & -120 & 7 & 10 & 16 & 24 & 20 & 26 \\
\hline 2000 & -44 & -58 & 3 & 4 & 8 & 10 & 8 & 12 \\
\hline $\begin{array}{l}2500 \\
3000\end{array}$ & -32 & -30 & 3 & 4 & 6 & 8 & 8 & 10 \\
\hline
\end{tabular}

$d z$ is taken as $1 \mathrm{~m}$.

* $E=\frac{\delta \rho}{d z}$

(The secondary spring layers of temperature and chlorinity are also found in nearly the same layer as this). This implies that the boundary layer between the western North Pacific Central Water mass (Sverdrup and others [6]) and the North Pacific Intermediate Water mass exists thereabout. While, at St. " $\mathrm{X}$ " no secondary maximum can be detected in vertical stability (or $d \sigma_{t} / d z$ ) as well as in $d T / d z$, but as to $d C l / d z$ it can be seen in a layer of about $200 \mathrm{~m}$ depth, and this depth gives information on the boundary between the upper mixing water mass and the Intermediate Water mass.

\section{Eddy conductivity and diffusivity}

If the annual variation of subsurface temperature such as illustrated in the previous section is due to the process of heat conduction, we can compute the eddy conductivity, $\mu$, applying FJELDSTAD's method [7]. The formula derived by him is

$$
\frac{\mu}{\rho}=\frac{n \theta}{A_{n}{ }^{2} \frac{\partial \alpha_{n}}{\partial z}} \int_{z}^{h} A_{n}{ }^{2} d z,
$$


where $\rho$ represents the density of water, $\theta=\frac{2 \pi}{\tau} \quad(\tau$ is the period length of the first harmonic term), $A_{n}$ is the amplitude of the $n$th harmonic term, $\alpha$ the phase lag, and $h$ the depth at which periodic temperature variations are supposed to vanish. The variation of $\mu$ with depth, which was obtained from the annual component of temperature variation, with $\rho=1.026$ (or 1.024) and $h=300$ (or 150) $\mathrm{m}$ for St. " $\mathrm{X}$ " (or St. " $\mathrm{T}$ ”), is shown by heavy line in Fig. 9. $\mu$ decreases rapidly

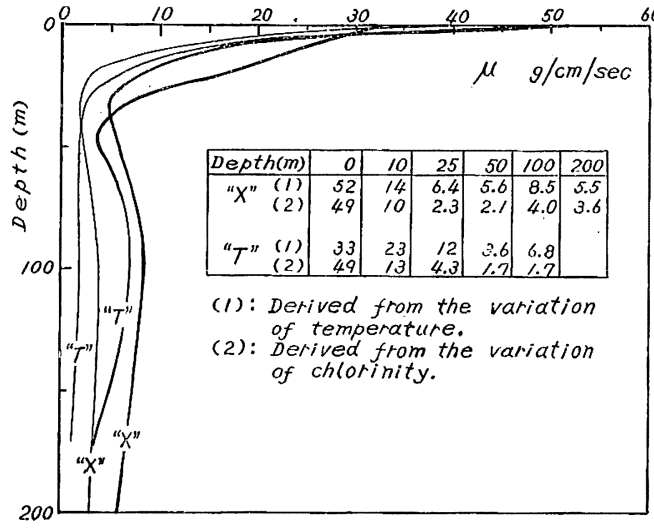

Fig. 9. Change of vertical eddy conductivity (diffusivity) with depth at Sts. "X" and " $\mathrm{T}$ ". The thick and the thin curves are based, respectively, on the values derived from the annual component of temperature variation and on the values derived from the chlorinity variation. Several of the numerical values of $\mu$ are inset in the blank space of the figure. from a considerably large value at the sea surface to a minimum in the vicinity of $30 \mathrm{~m} \mathrm{(St.} \mathrm{"X")} \mathrm{or} 50 \mathrm{~m}$ (St. " $\mathrm{T}$ ") depth and then slightly increases to a maximum in a layer of about $100 \mathrm{~m}$ depth. The depth of the minimum of $\mu$ nearly agrees with the depth layer in which the thermocline develops most intensely and consequently stratification of water is most stable. This is obvious from the fact that stable stratification reduces the vertical turbulence through which heat is transmitted.

If the transfer of chlorinity is similar to that of heat, the eddy diffusivity is to be equal to the eddy conductivity and, further, FJELDSTAD's method is to be applied for computing the eddy diffusivity to the annual variation of chlorinity. The values of the eddy diffusivity thus computed are shown by thin curves in Fig. 9. It can be seen from Fig. 9 that the variations in eddy conductivity and diffusivity with depth have a similar trend, though they do not agree in detail with each other.

However, it must be borne in mind that the use of the above equation is correct only when the advection term is independent of time and depth. This reservation will not be fully satisfied in the present case. In addition, the eddy conductivity (diffusivity) must vary not only with depth but also with seasons, and in autumn and winter generally the process of convection develops.

\section{Transparency and colour of the sea}

The transparency and colour of the sea, and their seasonal variations show, to some extent, characteristics proper to each region or water mass. The regional characteristics of the transparency and colour of the sea at St. "X" will be described in comparison with those at St. " $\mathrm{T}$ ”.

In the first place, the annual variations of the transparency and colour of the sea will be examined. In order to derive characteristic figures which would facilitate the comparison, harmonic analysis was done. The harmonic constants are shown in Table 5, where the symbols in the top line have the same meaning as in the previous section. Other components, whose constants are not tabulated here, are small in amplitude compared with the greatest component. The curves 
Table 5. Harmonic Constants of the Annual Variations of Transparency $(D)$ and Colour of the Sea $(F)$.

\begin{tabular}{|c|c|c|c|c|c|c|c|c|}
\hline & & $A_{0}$ & $A_{1}$ & $\alpha_{1}$ & $A_{2}$ & $\alpha_{2}$ & $100\left(\frac{A_{2}}{A_{1}}\right)$ & $R$ \\
\hline St “ $\mathrm{X}$ ” & $\left\{\begin{array}{l}D \\
F\end{array}(\mathrm{~m})\right.$ & $\begin{array}{r}21.9 \\
3.0\end{array}$ & $\begin{array}{l}3.0 \\
0.3\end{array}$ & $\begin{array}{c}281^{\circ} \\
67\end{array}$ & $\begin{array}{l}3.8 \\
0.4\end{array}$ & $\begin{array}{l}64^{\circ} \\
226\end{array}$ & $\begin{array}{l}127 \% \\
133\end{array}$ & $\begin{array}{l}0.5 \\
0.1\end{array}$ \\
\hline St. " $\mathrm{T}$ " & $\left\{\begin{array}{l}D(\mathrm{~m}) \\
F\end{array}\right.$ & $\begin{array}{r}31.2 \\
2.0\end{array}$ & $\begin{array}{l}7.9 \\
0.4\end{array}$ & $\begin{array}{r}231 \\
53\end{array}$ & $\begin{array}{l}0.8 \\
0.1\end{array}$ & $\begin{array}{r}74 \\
159\end{array}$ & $\begin{array}{l}10 \\
25\end{array}$ & $\begin{array}{l}0.9 \\
0.1\end{array}$ \\
\hline
\end{tabular}

based on the harmonic constants up to the semi-annual component are shown in Fig. 10 .

It can be seen from Fig. 10 and Table 5 that important differences exist between the two stations " $\mathrm{X}$ " and " $\mathrm{T}$ " in view of the annual variation of transparency. For St. "X", $A_{2}$ is greater than $A_{1}$, resulting in two maxima and two minima quite explicit in the curve of the annual variation. Namely, the transparency, reaching the principal minimum of $15 \mathrm{~m}$ in May, increases rapidly to the principal maximum of about $27 \mathrm{~m}$ in August, then decreases till November when the secondary minimum occurs, and again increases until the secondary maximum is reached in February. For St. " $\mathrm{T}$ ", on the other hand, $A_{2}$ is only 10 per cent of $A_{1}$, and the resultant curve - nearly the same as the curve of the annual component alone - shows only one maximum and one minimum; the maximum transparency takes place in late summer (about the same time as that of the principal maximum for St. "X") with a value of about $40 \mathrm{~m}$, and the minimum value is nearly $24 \mathrm{~m}$ occurring in March. The annual mean is $21.9 \mathrm{~m}$ at St. " $\mathrm{X}$ " and $31.2 \mathrm{~m}$ at St. " $\mathrm{T}$ ". The annual range is nearly $12 \mathrm{~m}$ at $\mathrm{St}$. "X", which is smaller than at St. " $\mathrm{T}$ " where it is about $16 \mathrm{~m}$.

As for the extremes of Secchi disc reading at St. "X", the highest one was $40 \mathrm{~m}$ (colour

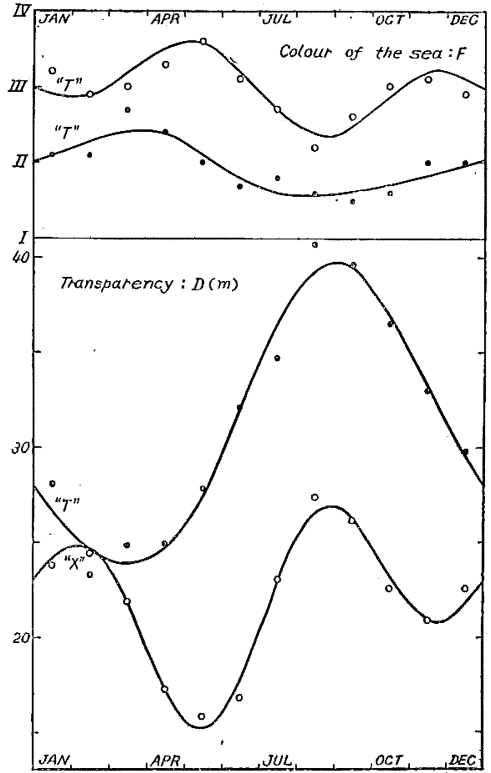

Fig. 10. Annual variations of transparency (lower part) and colour of the sea (upper part) at Sts. "X" and "T". Circles, open (for "X") and solid (for "T"), correspond to the "normal" monthly values; smooth curves are based on the values calculated from the harmonic constants shown in Table 5 . of the sea $(F): 2$, December 3, 1951) and the lowest $8 \mathrm{~m}$ (F: lack, April 17, 1948). For St. " $\mathrm{T}$ ", the highest transparency observed was $58 \mathrm{~m}(F: 1$, August 26, 1952) and the lowest $14 \mathrm{~m}$ ( $F: 3 \sim 4$, March 6, 1952).

Transparency changes mainly depending upon the amount of suspended materials in the sea. Though plankton organisms are obviously a part and not all, of the suspended materials in the sea, it has been found that a fairly good correlation exists between transparency and plankton volume (MARUmo [8], Korzumi [9]). 
Glancing at the curves in Fig. 10, we can find that the relation between the transparency and the colour of the sea is very close, especially for St. " $\mathrm{X}$ ". The frequency distributions of the transparency and colour of the sea are given in Table 6 . The values of $F$ that were recorded as $1 \sim 2,2 \sim 3$, etc. in the field

Table 6. Frequency Distributions of Transparency $(D)$ and Colour of the Sea $(F)$.

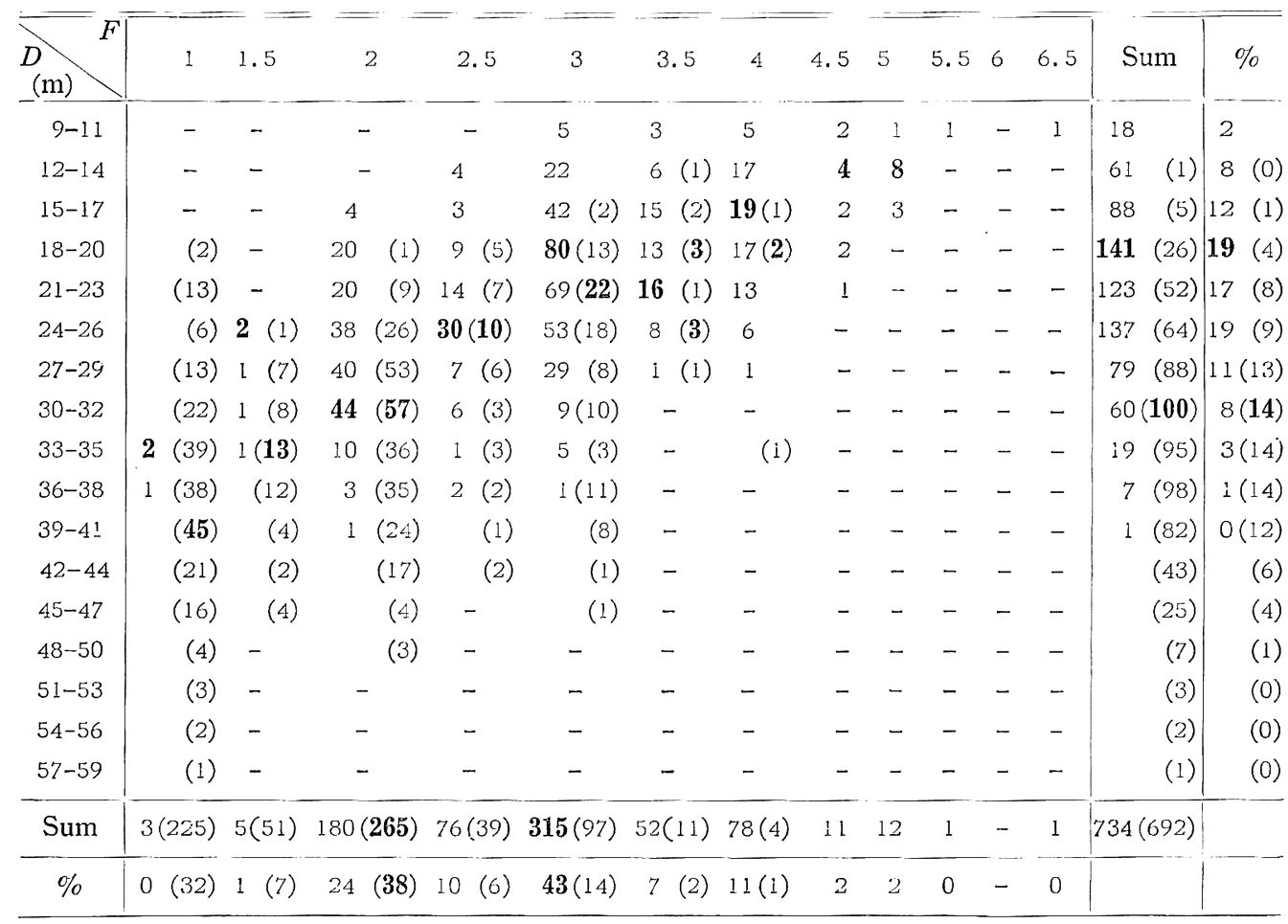

In each column, the values on the left-hand side are for St. "X" and those on the right-hand side (in parentheses) for St. " $\mathrm{T}$ ".

notes are included in the columns of $1.5,2.5$, etc. in this table. At St. " $X$ ", No. 3 on Forel scale is most frequently observed, whereas at St. " $T$ ", No. 2 is the most frequent. As seen from Table 7, the mean transparency for a given number on Forel scale is, on an average, about $5 \mathrm{~m}$ lower at St. "X" than at St. " $\mathrm{T}$ ". This fact suggests that the functional relation between the transparency and the colour of the sea is different according to sea regions. The colour of the sea depends, as is well known, not only upon the amount of suspended materials, but also upon the quality and size of them. So, the characteristics of planktological

Table 7. Mean Transparency $(D)$ for Each Number of Forel Scale $(F)$.

\begin{tabular}{|c|c|c|c|c|c|c|c|c|c|c|c|c|}
\hline$F$ & 1 & 1.5 & 2 & 2.5 & 3 & 3.5 & 4 & 4.5 & 5 & 5.5 & 6 & 6.5 \\
\hline$D(\mathrm{~m})\left\{\begin{array}{lll}(1) & \text { St } & \text { "X" } \\
(2) & \text { St. } & \text { T" }\end{array}\right.$ & $\begin{array}{c}(35.0) \\
36.5\end{array}$ & $\begin{array}{l}28.6 \\
35.0\end{array}$ & $\begin{array}{l}26.7 \\
32.7\end{array}$ & $\begin{array}{c}23.9 \\
(27.2)\end{array}$ & $\begin{array}{l}21.2 \\
28.3\end{array}$ & $\begin{array}{c}18.4 \\
(20.6)\end{array}$ & $\begin{array}{l}17.5 \\
22.0\end{array}$ & $\begin{array}{c}14.9 \\
-\end{array}$ & $\begin{array}{c}13.5 \\
-\end{array}$ & $\begin{array}{c}(10.0) \\
-\end{array}$ & $\begin{array}{l}- \\
-\end{array}$ & $\begin{array}{c}(10.0) \\
-\end{array}$ \\
\hline Difference $(2)-(1)$ & $(1.5)$ & 6.4 & 6.0 & $(3.3)$ & 7.1 & $(2.2)$ & 4.5 & - & - & - & - & - \\
\hline
\end{tabular}


conditions in the sea region concerned will play an important rôle in the functional relation between the transparency and the colour of the sea. The correlation coefficients were computed, giving -0.62 and -0.61 respectively for Sts. " $X$ " and " $\mathrm{T}$ ".

Acknowledgments _ - The author wishes to express his sincere thanks to Prof. Dr. K. Hidaka of Tokyo University, Prof. Dr. M. Uda of Tokyo University of Fisheries, and Dr. M. NAKANo of this Institute for their advice and encouragement during this work. Also to the observers and crew on board the ocean weather ships of the Central Meteorological Observatory, he is indebted for their valuable aid in many ways.

\section{References}

[1] Polifak, M. J., 1950 : Notes on Determining the Depths of Sampling in Serial Oceanographic Observations. Journ. Mar. Res., 9, p. 17.

[2] UDA, M., 1935: The Results of Simultaneous Oceanographical Investigations in the North Pacific Ocean Adjacent to Japan made in August 1933. Journ. Imp. Fish. Exp. Sat., No. 6. $130 \mathrm{pp}$.

[3] Fleming, J. A., H. U. Sverdrup, C. C. Ennis, S. L. Seaton, and W. C. Hendrix, 1945 : Scientific Results of Cruise VII of the Carnegie during 1928 1929. Oceanography-I-B, Observations and Results in Physical Oceanography. Carnegie Institution of Washington, Publ. 545.

[4] Yamagiwa, T., 1951: Variation of the Flow in the Intermediate Water at the Fixed Point $153^{\circ} \mathrm{E}, 39^{\circ}$ N. Journ. Oceanogr. Soc. Japan, 6, p. 160.

[5] Koizumi, M., 1951 : On the Oceanographical Conditions around the Fixed Point “X-Ray" (1948 to 1949). Oceanogr. Rep. Centr. Met. Obs. Japan, 2, p. 69.

[6] Sverdrup, H. U., M. W. Johnson, and R. H. Fleming, 1942: The Oceans. Prentice-Hall, Inc., New York. 1087 pp.

[7] Fueidstad, J. E., 1933: Wärmeleitung im Meere. Geofysiske Publikasjoner, 10, No. 7, $20 \mathrm{pp}$.

[8] Marumo, R., 1951: On the Correlation between Plankton Volume and Transparency in the Neighbouring Seas of Japan. Journ. Oceanogr. Soc. Japan, 7, p. 9.

[9] Konzum, M. 1952: The Annual Variation in and Correlation between Colour of the Sea, Transparency, and Plankton Volume around the Fixed Point "Extra". Journ. Oceanogr. Soc. Japan, 8, p. 79. 